\title{
OPTIMAL ALTERNATIVE SELECTION MODELS IN A MULTI-STAGE DECISION-MAKING PROCESS
}

\author{
Oksana Mulesa \\ Department of Cybernetics and Applied Mathematics ${ }^{l}$ \\ Oksana.Mulesa@uzhnu.edu.ua \\ Vitaliy Snytyuk \\ Department of Intelligent Technologies \\ Taras Shevchenko National University of Kyiv \\ 60 Volodymyrska str., Kyiv, Ukraine, 01033 \\ snytyuk@gmail.com \\ Ivan Myronyuk \\ Department of Health Sciences ${ }^{1}$ \\ ivan.myronyuk@uzhnu.edu.ua \\ ${ }^{1}$ Uzhhorod National University \\ 3 Narodna sq., Uzhhorod, Ukraine, 88000
}

\begin{abstract}
Management decision-making tasks are usually characterized by a high level of uncertainty. When solving this class of problems, it is necessary to take into account the environmental conditions for the implementation of the decisions made and the consequences that may arise in this case. The decision-making task in the face of uncertainty can be represented in the form of a "game with nature", in which the optimal player strategy is sought.

A two-stage decision-making process is considered, in which at each stage the decision-making problem is solved in conditions of risk. The case is supposed in which, after making a decision at the first stage, choosing an effective alternative and the onset of a certain state of nature, it is necessary to solve the decision-making problem of the second stage.

Decision-making models based on well-known decision models of the "game with nature" are proposed. The developed models allow in the process of choosing an effective alternative to the first stage to assess the possible consequences of such a choice, taking into account the expectations of the decision maker.

In the course of experimental verification, it is shown that the developed decision-making models can be used to solve such multi-stage problems, the phased solution of which is incorrect. This may occur due to the fact that some of their stages are associated with certain losses, and others - with profit. In such situations, it is advisable to consider the problem as a whole and at each stage, take into account all available information as much as possible.
\end{abstract}

Keywords: hierarchical decision-making process, "game with nature", decision-making models.

DOI: $10.21303 / 2461-4262.2019 .001005$

\section{Introduction}

One of the most complex functions of a manager, regardless of its field of activity, is the need to develop and make managerial decisions in conditions of high-level uncertainty. When making such a decision, the environmental conditions in which the implementation of this decision will take place and the possible consequences of its implementation are taken into account. In this case, it is necessary to take into account the dynamism of the conditions, as well as the fact that the vector and the depth of their changes in time are most often impossible to take into account. At the same time, the development of a managerial decision should always take place on the basis of the existing situation (based on the results of a situational analysis), the results of assessing the likely possible changes in the environment (options for predicting the situation). Important in this case is the experience and consequences of the implementation of a decision (both the personal experience of the decision-maker (DM) and the experience of others).

The problem of making managerial decisions can be mathematically formulated as the problem of making decisions in the face of uncertainty [1-3]. Depending on the characteristics of the 
source data, the decision-making task in conditions of risk and the decision-making task in conditions of uncertainty are shared. In a number of studies [4, 5], decision-making problems in the face of uncertainty are considered in the form of a game with nature. Among the methods that are proposed in scientific papers for choosing the best alternatives are guaranteed payoff methods [6], methods based on the provisions of probability theory $[7,8]$, methods of the theory of fuzzy sets $[9,10]$, etc.

However, a number of management tasks require a breakdown of the decision-making process into several stages [7, 11]. In such cases, it is advisable to analyze the risks and gains that arise at each stage. The development of effective models for choosing the best alternatives in hierarchical decision-making tasks will allow taking into account the consequences of decisions made throughout the entire process of analyzing a task.

The aim of research is development and studying models of the hierarchical decision-making process based on well-known criteria for choosing optimal alternatives in the face of uncertainty and risk. Achieving this aim is achieved by solving the following tasks:

- perform a formalized formulation of the task of one-stage and two-stage selection of the best alternative in the game with nature;

- develop models for choosing optimal alternatives for the task of making two-stage decisions based on well-known conditions;

- perform a comparative analysis of the developed models.

\section{The task of decision making under risk and uncertainty}

The mathematical model of the decision-making problem under uncertainty can be constructed in the form of a special "game with nature" in which the optimal player strategy is sought, and the optimal nature strategy is not considered $[3,4]$. The output of such a task can be written as a tuple

$$
\langle X, S, u(x, s)\rangle
$$

where $X$ - the set of alternatives, $S$ - the set of states of nature; $u(x, s)$ - a utility function that expresses the expected utility of alternative x provided that the state of nature s occurs.

In the event that there are ways to assess the probability distribution of the onset of natural conditions, the problem of decision making arises in risk conditions, which can be set in this form:

$$
\langle X, S, u(x, s), p(s)\rangle
$$

where $p(s)$ - the probability of occurrence of state $s$.

A feature of this task is that the elements of the set $S$ form a complete group of events, that is, the conditions are satisfied for them:

$$
\begin{gathered}
s_{i} \cap s_{j}=\varnothing, \forall s_{i}, s_{j} \in S: i \neq j, \\
\sum_{s \in S} p(s)=1 .
\end{gathered}
$$

A decision must be made on choosing the best alternative.

The statement of the problem in the form of (1)-(4) provides that the DM has data only on possible states of nature. At the same time, the player - DM - acts to select the solution that is most satisfactory to itself, and nature displays its states spontaneously and objectively, without opposing the player [4].

Then, in the case of finiteness of a multitude of alternatives and a multitude of states, the DM win matrix can be presented in the form of the Table 1. 
Table 1

DM win matrix

\begin{tabular}{|c|c|c|c|c|}
\hline \multirow{2}{*}{ Alternatives } & \multicolumn{4}{|c|}{ States } \\
\hline & $\mathrm{s}_{1}$ & $\mathrm{~S}_{2}$ & ... & $\mathrm{s}_{\mathrm{m}}$ \\
\hline $\mathrm{x}_{1}$ & $\mathrm{u}\left(\mathrm{x}_{1}, \mathrm{~s}_{1}\right)$ & $\mathrm{u}\left(\mathrm{x}_{1}, \mathrm{~s}_{2}\right)$ & $\ldots$ & $\mathrm{u}\left(\mathrm{x}_{1}, \mathrm{~s}_{\mathrm{m}}\right)$ \\
\hline $\mathrm{x}_{2}$ & $\mathrm{u}\left(\mathrm{x}_{2}, \mathrm{~s}_{1}\right)$ & $\mathrm{u}\left(\mathrm{x}_{2}, \mathrm{~s}_{2}\right)$ & $\ldots$ & $\mathrm{u}\left(\mathrm{x}_{2}, \mathrm{~s}_{\mathrm{m}}\right)$ \\
\hline$\cdots$ & $\cdots$ & $\cdots$ & $\cdots$ & $\cdots$ \\
\hline $\mathrm{x}_{\mathrm{n}}$ & $\mathrm{u}\left(\mathrm{x}_{\mathrm{n}}, \mathrm{s}_{1}\right)$ & $\mathrm{u}\left(\mathrm{x}_{\mathrm{n}}, \mathrm{s}_{2}\right)$ & $\ldots$ & $\mathrm{u}\left(\mathrm{x}_{\mathrm{n}}, \mathrm{s}_{\mathrm{m}}\right)$ \\
\hline Probabilities & $\mathrm{p}\left(\mathrm{s}_{1}\right)$ & $\mathrm{p}\left(\mathrm{s}_{2}\right)$ & $\ldots$ & $\mathrm{p}\left(\mathrm{s}_{\mathrm{m}}\right)$ \\
\hline
\end{tabular}

Note: $n=|X|<\infty, m=|S|<\infty$, respectively, the cardinalities of the set of alternatives $X$ and the set of states $S$

A number of criteria for choosing the optimal strategy $x^{*}$ are proposed in scientific sources [2-4]. The choice of criterion depends on the risk appetite of the decision maker, on the desire to minimize possible losses and other conditions.

\section{Construction of a mathematical model of a two-stage decision-making problem}

Let's consider a two-stage decision-making process in which at each stage the decision-making problem is solved under conditions of risk. Let's imagine the decision-making task of the first stage, as before, in the form of the Table 1.

Let's simulate a situation in which, after making a decision at the first stage and choosing some alternative to the onset of a certain state of nature, it is necessary to implement the second stage of decision making. At this stage, depending on the results of the first stage, the decision-making problem is solved under conditions of risk, which let's present in the form of the Table 2.

Table 2

Decision making task for the second stage

\begin{tabular}{|c|c|c|c|c|}
\hline \multirow{2}{*}{ Alternatives } & \multicolumn{4}{|c|}{ States } \\
\hline & $t_{1}$ & $\mathrm{t}_{2}$ & $\ldots$ & $\mathrm{t}_{\mathrm{w}}$ \\
\hline $\mathrm{y}_{1}^{(\mathrm{i})}$ & $\mathrm{u}_{\mathrm{ij}}\left(\mathrm{y}_{1}^{(\mathrm{i})}, \mathrm{t}_{1}\right)$ & $\mathrm{u}_{\mathrm{ij}}\left(\mathrm{y}_{1}^{(\mathrm{i})}, \mathrm{t}_{2}\right)$ & $\ldots$ & $\mathrm{u}_{\mathrm{ij}}\left(\mathrm{y}_{1}^{(\mathrm{i})}, \mathrm{t}_{\mathrm{w}}\right)$ \\
\hline $\mathrm{y}_{2}^{(\mathrm{i})}$ & $\mathrm{u}_{\mathrm{ij}}\left(\mathrm{y}_{2}^{(\mathrm{i})}, \mathrm{t}_{1}\right)$ & $\mathrm{u}_{\mathrm{ij}}\left(\mathrm{y}_{2}^{(\mathrm{i})}, \mathrm{t}_{2}\right)$ & $\cdots$ & $\mathrm{u}_{\mathrm{ij}}\left(\mathrm{y}_{2}^{(\mathrm{i})}, \mathrm{t}_{\mathrm{w}}\right)$ \\
\hline$\ldots$ & $\ldots$ & $\ldots$ & $\ldots$ & $\ldots$ \\
\hline $\mathrm{y}_{\mathrm{n}_{\mathrm{i}}}^{(\mathrm{i})}$ & $\mathrm{u}_{\mathrm{ij}}\left(\mathrm{y}_{\mathrm{n}_{\mathrm{i}}}^{(\mathrm{i})}, \mathrm{t}_{1}\right)$ & $\mathrm{u}_{\mathrm{ij}}\left(\mathrm{y}_{\mathrm{n}_{\mathrm{i}}}^{(\mathrm{i})}, \mathrm{t}_{2}\right)$ & $\cdots$ & $\mathrm{u}_{\mathrm{ij}}\left(\mathrm{y}_{\mathrm{n}_{\mathrm{i}}}^{(\mathrm{i})}, \mathrm{t}_{\mathrm{w}}\right)$ \\
\hline Probabilities & $\mathrm{p}\left(\mathrm{t}_{1} / \mathrm{s}_{\mathrm{j}}\right)$ & $\mathrm{p}\left(\mathrm{t}_{2} / \mathrm{s}_{\mathrm{j}}\right)$ & $\ldots$ & $\mathrm{p}\left(\mathrm{t}_{\mathrm{w}} / \mathrm{s}_{\mathrm{j}}\right)$ \\
\hline
\end{tabular}

Mathematical models (MM) of decision making are proposed, which allow to assess the possible consequences of such a choice in the process of choosing an effective alternative to the first stage, taking into account the expectations of DM and its risk appetite.

$M M 1$. Selection based on minimax criterion. First, for each alternative, the function values are calculated: 


$$
E_{1}\left(x_{i}\right)=\min _{s_{j}, j=1, m}\left(u\left(x_{i}, s_{j}\right)+\max _{y_{k}^{(i)}, k=1, n_{i}} \min _{t_{v}, v=1, w} u_{i j}\left(y_{k}^{(i)}, t_{v}\right)\right)
$$

The choice of the optimal alternative at the first stage is carried out according to this model:

$$
x^{*} \in \operatorname{Arg} \max _{x_{i}, i=1, n} E_{1}\left(x_{i}\right)=\operatorname{Arg} \max _{x_{i}, i=1, n}\left(\min _{s_{j}, j=1, m}\left(u\left(x_{i}, s_{j}\right)+\max _{y_{k}^{(i)}, k=1, n_{i}} \min _{t_{v}, v=1, w} u_{i j}\left(y_{k}^{(i)}, t_{v}\right)\right)\right) .
$$

The alternatives chosen in this way exclude risk, that is, with any development of the game, the resulting utility can't be less $E_{1}\left(x^{*}\right)$.

$M M$ 2. Selection based on the Bayes-Laplace criterion. According to this criterion, at the first stage, for each alternative, the sum of the mathematical expectations of the usefulness of its consequences of the first and second stages is calculated by the formula:

$$
E_{2}\left(x_{i}\right)=\sum_{j=1}^{m}\left(u\left(x_{i}, s_{j}\right)+\max _{y_{k}^{(i)}, k=\overline{1, n_{i}}} \sum_{v=1}^{w} p\left(t_{v} / s_{j}\right) u_{i j}\left(y_{k}^{(i)}, t_{v}\right)\right) \cdot p\left(s_{j}\right)
$$

and the choice of the optimal alternative is as follows:

$$
x^{*} \in \operatorname{Arg} \max _{x_{i}, i=1, n} E_{2}\left(x_{i}\right)=\operatorname{Arg} \max _{x_{i}, i=1, n}\left(\sum_{j=1}^{m}\left(u\left(x_{i}, s_{j}\right)+\max _{y_{k}^{(i)}, k=1, n_{i}} \sum_{v=1}^{w} p\left(t_{v} / s_{j}\right) u_{i j}\left(y_{k}^{(i)}, t_{v}\right)\right) \cdot p\left(s_{j}\right)\right) .
$$

The condition for the effective application of this criterion is the case when the solution is implemented a large number of times. For a small number of solutions, some risk is allowed.

MM 3. Selection based on the criterion of minimizing the variance of the estimates. This criterion should be used when it is necessary to make a sustainable decision. According to this criterion, for each alternative, the sum of the variances of the utility functions of its consequences in the first and second stages is calculated:

$$
E_{3}\left(x_{i}\right)=\sum_{j=1}^{m} p\left(s_{j}\right) \cdot\left(u\left(x_{i}, s_{j}\right)+\max _{y_{k}^{(i), k=1, n_{i}} t_{v}, v=1, w} \min _{i j}\left(y_{k}^{(i)}, t_{v}\right)-E_{1}\left(x_{i}\right)\right)^{2}
$$

Then the choice of the optimal alternative should be carried out as follows:

$$
x^{*} \in \operatorname{Arg} \min _{x_{i}, i=1, n} E_{3}\left(x_{i}\right)=\operatorname{Arg} \min _{x_{i}, i=1, n} \sum_{j=1}^{m} p\left(s_{j}\right) \cdot\left(u\left(x_{i}, s_{j}\right)+\max _{y_{k}^{(i)}, k=1, n_{i}} \min _{t_{v}, v=1, w} u_{i j}\left(y_{k}^{(i)}, t_{v}\right)-E_{1}\left(x_{i}\right)\right)^{2} .
$$

The conditions for the effectiveness of this criterion are similar to the conditions for the Bayes-Laplace criterion.

MM 4. The choice based on the modal criterion involves considering only the most likely states of nature at each stage of decision making. The calculations are carried out in several steps.

First, let's find the most likely state of nature of the first stage:

$$
s^{*} \in \operatorname{Arg} \max _{s_{j}, j=1, m} p\left(s_{j}\right) .
$$

Next, let's find most likely the state of nature of the second stage, provided that the state $s^{*}$ has arrived:

$$
t^{*} \in \operatorname{Arg} \max _{t_{v}, v=1, w} p\left(t_{v} / s^{*}\right)
$$


After $s^{*}$ and $t^{*}$ are fixed, for each alternative of the first stage let's calculate the value of the function:

$$
E_{4}\left(x_{i}\right)=u\left(x_{i}, s^{*}\right)+\max _{y_{k}^{(i)}, k=1, n_{i}} u_{i j^{*}}\left(y_{k}^{(i)}, t^{*}\right)
$$

where $j^{*}-$ the state $s^{*}$ serial number.

Let's find the best alternative using the model:

$$
x^{*} \in \operatorname{Arg} \max _{x_{i}, i=1, n} E_{4}\left(x_{i}\right)=\operatorname{Arg} \max _{x_{i}, i=1, n}\left(u\left(x_{i}, s^{*}\right)+\max _{y_{k}^{(i)}, k=1, n_{i}} u_{i j}\left(y_{k}^{(i)}, t^{*}\right)\right) \text {. }
$$

The advantages of this approach are that for its application it is not necessary to know the entire probability distribution of the onset of natural states, but rather determine the most likely state.

\section{Comparative analysis of the results of the application of the developed models}

Let's consider the model problem of two-stage decision making.

Let a situational analysis of the provision of medical care to the population of a certain territory be carried out to show a shortage of a certain type of medical services. Possible solutions to meet this demand are the opening of new facilities providing medical services (health facilities, medical centers, offices). However, the opening of a medical institution (multidisciplinary clinic, single-discipline medical office) requires certain material costs, and can also be extended over time. Thus, at the stage of deciding what type of institution it is advisable to open, it is proposed to evaluate the possible effectiveness of the decisions made.

Let the task of the first stage be presented in the form of the Table 3, where income (expense) is shown in conventional monetary units.

Table 3

The task of the first stage

\begin{tabular}{ccc}
\hline $\mathbf{x} / \mathbf{s}$ & $\mathbf{s}_{\mathbf{1}}$ & $\mathbf{s}_{\mathbf{2}}$ \\
\hline$x_{1}$ & -40 & -65 \\
$x_{2}$ & -100 & -150 \\
$p\left(s_{j}\right)$ & 0,70 & 0,30
\end{tabular}

Note: possible solutions are: $x_{1}=«$ Opening a medical office»; $x_{2}=«$ Opening a medical clinic $»$

During the implementation of the decision, one of the following environmental conditions is possible: $s_{1}=\ll$ Stable socio-economic conditions $», s_{2}=\ll$ Negative change in socio-economic conditions».

After the implementation of the decision taken at the first stage, the need for solving one of the tasks of the second stage, which are given in Tables 4-7, where the forecast values of the profits received during a certain period of time are indicated.

Table 4

The problem that arises when choosing an alternative $x_{1}$ and the onset of state $s_{1}$

\begin{tabular}{ccc}
\hline $\mathbf{y} / \mathbf{t}$ & $\mathbf{t}_{\mathbf{1}}$ & $\mathbf{t}_{\mathbf{2}}$ \\
\hline$y_{1}$ & 45 & 50 \\
$y_{2}$ & 30 & 100 \\
$p\left(t_{v} / s_{1}\right)$ & 0.20 & 0.80
\end{tabular}


Table 5

The problem that arises when choosing an alternative $x_{1}$ and the onset of state $s_{2}$

\begin{tabular}{ccc}
\hline $\mathbf{y} / \mathbf{t}$ & $\mathbf{t}_{\mathbf{1}}$ & $\mathbf{t}_{2}$ \\
\hline$y_{1}$ & 50 & 65 \\
$y_{2}$ & 70 & 120 \\
$p\left(t_{v} / s_{2}\right)$ & 0.60 & 0.40
\end{tabular}

Table 6

The problem that arises when choosing an alternative $x_{2}$ and the onset of state $s$

\begin{tabular}{ccc}
\hline $\mathbf{y} / \mathbf{t}$ & $\mathbf{t}_{\mathbf{1}}$ & $\mathbf{t}_{\mathbf{2}}$ \\
\hline$y_{1}$ & 110 & 120 \\
$y_{2}$ & 70 & 200 \\
$p\left(t_{v} / s_{1}\right)$ & 0.20 & 0.80
\end{tabular}

Table 7

The problem that arises when choosing an alternative $x_{2}$ and the onset of state $s_{2}$

\begin{tabular}{ccc}
\hline $\mathbf{y} / \mathbf{t}$ & $\mathbf{t}_{\mathbf{1}}$ & $\mathbf{t}_{\mathbf{2}}$ \\
\hline$y_{1}$ & 165 & 170 \\
$y_{2}$ & 150 & 300 \\
$p\left(t_{v} / s_{2}\right)$ & 0.60 & 0.40
\end{tabular}

Tables 4-7 indicate alternatives $y y_{1}=«$ Sale of equipped premises $», y_{2}=\ll$ Doing your own business»; in the process of implementing the decisions made, the following environmental conditions are possible: $s_{1}=$ «Negative change in demand for medical services",$s_{2}=$ «Conservation of demand for medical services».

In order to demonstrate the progress of solving the problem, let's perform calculations according to MM 1:

$$
\begin{gathered}
E_{1}\left(x_{1}\right)=\min \{-40+\max \{45,30\},-65+\max \{50,70\}\}=\min \{5,5\}=5 . \\
E_{1}\left(x_{2}\right)=\min \{-100+\max \{110,70\},-150+\max \{165,150\}\}=\min \{10,15\}=15 .
\end{gathered}
$$

Then, by (6), the optimal alternative is $x_{2}$ with a guaranteed payoff of 15 .

On the other hand, in accordance with the usual minimax criterion, for the task given in Table 3, the optimal alternative is $x_{1}$.

The results of applying this and other rules are given in Table $\mathbf{8}$.

Table 8

Problem solving results

\begin{tabular}{cccc}
\hline Rule & $\mathbf{E}\left(\mathbf{x}_{1}\right)$ & $\mathbf{E}\left(\mathbf{x}_{2}\right)$ & Optimal alternative \\
\hline 1 & $E_{1}\left(x_{1}\right)=5$ & $E_{1}\left(x_{2}\right)=15$ & $x_{2}$ \\
2 & $E_{2}\left(x_{1}\right)=39.7$ & $E_{1}\left(x_{2}\right)=69.8$ & $x_{2}$ \\
3 & $E_{3}\left(x_{1}\right)=0$ & $E_{3}\left(x_{2}\right)=7.5$ & $x_{1}$ \\
4 & $E_{4}\left(x_{1}\right)=60$ & $E_{4}\left(x_{2}\right)=100$ & $x_{2}$
\end{tabular}

Thus, $x_{2}$ is the optimal alternative to compliance with the three rules, and the models proposed above allow taking into account all the initial data of the task. 
On the other hand, given the specifics of the Table 3, it can be argued that the use of any of the known methods for solving the "game with nature" would lead to the fact that the alternative $x_{1}$ would be an effective alternative. Such a decision would arise because the strategy corresponding to it dominates. However, this approach does not allow in any way to take into account the consequences of decisions made at the subsequent stages of the decision-making process.

\section{Discussion of the results of the development of models for the selection of optimal alterna- tives for the task of making two-stage decisions}

Existing methods of solving "games with nature" allow decisions to be made only because of the value of the utility function, which takes place at the decision-making stage $[2,3]$. In contrast to such approaches, the two-stage decision-making models developed in this article allow to take into account the utility functions of all stages of decision-making. This is achieved due to the fact that when calculating the expected utilities of the given alternatives, an analysis is made of the effectiveness of all possible solutions to decision-making problems that may arise in the process under consideration.

The proposed models for determining optimal alternatives in two-stage decision-making (5)-(13) are based on well-known decision-making methods in conditions of risk and uncertainty. Thus, the developed rules are based on the same assumptions and characteristics of the decision maker, as well as known methods.

During the experimental verification (Tables 3-7), the decision-making problem was considered, the phased solution of which is incorrect due to the fact that its first stage is associated with certain losses (investments), and the second - with profit. The use of the developed models (5)-(13) to solve the two-stage decision-making problem makes it possible to take into account all available information and determine the optimal alternative.

\section{Conclusions}

A multi-stage decision-making task can be formulated in the form of sequential "games with nature". This approach allows to consider nature as an independent player, and therefore encourages to take into account the random or probabilistic nature of its actions.

The mathematical formulation of the problem of one- and two-stage decision making is performed. It is shown that at the next stages it is advisable to take into account all the possible consequences of decisions made at the previous stages, as well as the occurrence of certain events.

The developed models for choosing optimal alternatives to the two-stage decision-making problems are based on such well-known methods of solving "games with nature" as the minimax criterion, modal criterion, Bayes-Laplace criterion, etc. The use of the developed models is associated with assessing the possible consequences of the second stage, depending on the accepted at the first stage of the decision, and determining, depending on this, the optimal alternative to the first stage. This approach allows to take into account all the information available at the first stage, and such features of the decision maker as risk appetite, pessimism or optimism, and the like.

On the model problem, the expediency of using the developed models for choosing the optimal alternatives for the tasks associated with making investments and making a profit has been demonstrated. It is proved that in the given case, the application of well-known decision-making methods would lead to a deterioration of the results.

\section{References}

[1] Murphy, A., Katz, R. W. (2019). Probability, statistics, and decision making in the atmospheric sciences. CRC Press, 547.

[2] Hnatienko, H. M., Snytiuk, V. Ye. (2008). Ekspertni tekhnolohiyi pryiniattia rishen. Kyiv: TOV «Maklaut», 444.

[3] Voloshyn, O. F., Mashchenko, S. O. (2010). Modeli ta metody pryiniattia rishen. Kyiv: Vydavnycho-polihrafichnyi tsentr «Kyivskyi universytet», 336 .

[4] Emets, O. A., Ust'yan, N. Yu. (2008). Igry s kombinatornymi ogranicheniyami. Kibernetika i sistemniy analiz, 4, 134-141.

[5] Colman, A. M. (2016). Game theory and experimental games: The study of strategic interaction. Elsevier, 314.

[6] Nowik, I., Nowik, T. (2017). Games with Costly Winnings. International Game Theory Review, 19 (04), 1750016. doi: https:// doi.org/10.1142/s0219198917500165 
[7] Busemeyer, J. R., Wang, Z., Shiffrin, R. M. (2015). Bayesian model comparison favors quantum over standard decision theory account of dynamic inconsistency. Decision, 2 (1), 1-12. doi: https://doi.org/10.1037/dec0000017

[8] Meier, K. J., Favero, N., Zhu, L. (2015). Performance Gaps and Managerial Decisions: A Bayesian Decision Theory of Managerial Action. Journal of Public Administration Research and Theory, 25 (4), 1221-1246. doi: https://doi.org/10.1093/jopart/muu054

[9] Mulesa, O., Geche, F., Batyuk, A., Buchok, V. (2018). Development of Combined Information Technology for Time Series Prediction. Advances in Intelligent Systems and Computing, 361-373. doi: https://doi.org/10.1007/978-3-319-70581-1_26

[10] Jing, L., Li, Z., Peng, X., Li, J., Jiang, S. (2019). A Relative Equilibrium Decision Approach for Concept Design Through Fuzzy Cooperative Game Theory. Journal of Computing and Information Science in Engineering, 19 (4). doi: https://doi.org/ $10.1115 / 1.4042837$

[11] Sitorus, F., Cilliers, J. J., Brito-Parada, P. R. (2019). An integrated constrained fuzzy stochastic analytic hierarchy process method with application to the choice problem. Expert Systems with Applications, 138, 112822. doi: https://oi.org/10.1016/ j.eswa.2019.112822

\title{
APPLICATION OF A CONVOLUTIONAL NEURAL NETWORK TO CREATE A DETECTOR OF TECHNICAL ANALYSIS FIGURES ON EXCHANGE QUOTES CHARTS
}

\author{
Victor Skuratov \\ All-Russian Research Institute of Radio Engineering \\ 22 Bol'shaya Pochtovaya str., Moscow, Russian Federation, 105082 \\ viktor.skuratov@gmail.com \\ Konstantin Kuzmin \\ Department of "Mathematical and instrumental methods in economics" \\ University of Russian Innovation Education \\ 10 Krasnobogatyrskaya str., Moscow, Russia, 107061 \\ konstantin.alexandrovich@yahoo.com \\ Igor Nelin \\ Department "Radiolocation, radio navigation and on-board radio electronic equipment" \\ Moscow Aviation Institute \\ 4 Volokolamskoe shosse, Moscow, Russian Federation, 125993 \\ nelin.iv@yandex.ru \\ Mikhail Sedankin \\ State Research Center - Burnasyan Federal Medical Biophysical Center of \\ Federal Medical Biological Agency \\ 23 Marshala Novikova str., Moscow, Russia, 123098 \\ msedankin@yandex.ru
}

\footnotetext{
Abstract

Today, the use of artificial intelligence based on neural networks is the most effective approach to solving image recognition problems. The possibility of using a convolutional neural network to create a pattern detector for technical analysis based on stock chart data has been investigated. The found figures of technical analysis can serve as the basis for making trading decisions in the financial markets. In the conditions of an ever-growing array of various information, the use of visual data reading tools is becoming more and more expedient, as it allows to speed up the process of searching and processing the necessary information for decision-makers. The modeling process, analysis, and results of applying the pattern detector of technical analysis are presented. The
} 